\section{Evaluation of surgically assisted rapid maxillary expansion with and without midpalatal split}

L. F. M. Sant'Ana, C. R. M. Pinzan-Vercelino, J. A. Gurgel, P. S. P. Carvalho: Evaluation of surgically assisted rapid maxillary expansion with and without midpalatal split. Int. J. Oral Maxillofac. Surg. 2016; 45: 997-1001. (C) 2016 Published by Elsevier Ltd on behalf of International Association of Oral and Maxillofacial Surgeons.

Abstract. The purpose of this study was to compare the efficacy and the patients' subjective symptomatology between surgically assisted rapid maxillary expansion (SARME) with midpalatal split and SARME without midpalatal split. The sample consisted of 24 consecutive adult patients requiring treatment with SARME, who were divided into two groups. Group 1 patients $(n=14)$ underwent SARME with midpalatal split, and group 2 patients $(n=10)$ underwent SARME without midpalatal separation. The efficacy of the technique was assessed in relation to the presence of a diastema between the upper incisors and radiographic evidence of separation of the maxillary bones in the midpalatal suture. The patients' symptomatology was evaluated using pain scores. The results demonstrated a greater efficacy for group $1(P=0.00)$. The discomfort of surgery assessed immediately postoperative and at 14 days postoperative was similar in the two groups. Both surgical techniques were tolerated by the patients; the midpalatal separation did not influence patient discomfort due to surgery. The two groups showed a statistically significant difference regarding discomfort during appliance activation and pain during the postoperative phase, with group 2 showing greater discomfort.
L. F. M. Sant'Ana ${ }^{1}$,

C. R. M. Pinzan-Vercelino², J. A. Gurgel ${ }^{2,3}$, P. S. P. Carvalho 4

${ }^{1}$ Pontifícia Universidade Católica, Campinas, São Paulo, Brazil; ${ }^{2}$ Division of Orthodontics, University Ceuma, São Luís, Maranhão, Brazil; ${ }^{3}$ State University of São Paulo, Marília, São Paulo, Brazil; ${ }^{4}$ Division of Stomatology and Oral Surgery, Bauru Dental School, University of São Paulo, Bauru, São Paulo, Brazil

Key words: surgically assisted rapid maxillary expansion; surgical procedures; operative; efficacy.

Accepted for publication 9 March 2016 Available online 26 March 2016
Rapid maxillary expansion has been used effectively to correct transverse maxillary discrepancies in children and adolescents up to the pubertal stage. ${ }^{1}$ With skeletal maturity there is an increase in midpalatal suture resistance and a reduction in facial skeletal flexibility. ${ }^{2,3}$ Consequently, orthopaedic maxillary expansion is more difficult to achieve, ${ }^{1,3}$ and in some cases it is feasible only with surgical procedures. ${ }^{4-12}$ It is important to highlight that individual variability in the fusion of the midpalatal suture can occur, and this individual variability is not directly related to age, particularly in young adults. ${ }^{13,14}$ An accurate diagnosis, including individual assessment of the maturation of the midpalatal suture, ${ }^{14}$ must be performed to determine whether a patient is a suitable candidate for either conventional or surgically assisted rapid maxillary expansion. ${ }^{14,15}$

Despite well-defined indications for surgically assisted rapid maxillary expansion (SARME), a wide variety of surgical approaches exist, and there is currently no consensus regarding the surgical approach 
to use. ${ }^{8,16}$ Surgeons often determine the surgical technique based on their experience and preference, which leads to considerable variations. ${ }^{10,17}$ The use of combined osteotomies in the anterior and lateral areas of the maxilla, in the suture, and in the pterygomaxillary regions in order to allow maxillary expansion in adult patients has been reported in the literature.

The surgeries are principally based on the areas of resistance to maxillary disjunction. The midpalatal suture is not considered the principal area, but it is one of the areas of resistance to maxillary expansion. Recently, Lee et al. demonstrated the high stress concentration in the midpalatal suture during maxillary expansion, using finite element models. ${ }^{3}$ Previous studies have compared surgeries performed with and without pterygomaxillary disjunction, because the pterygoid junction is one of the areas of resistance to maxillary expansion.,18-20 However, analysis of the midpalatal separation is lacking. ${ }^{9,21,22}$ Freitas et al. ${ }^{9}$ and Chung and Goldman ${ }^{22}$ evaluated surgery involving the midpalatal split; however, they did not compare the results of midpalatal split surgery with the results of surgery without the midpalatal split.

One method of surgical midpalatal split is performed with a chisel. ${ }^{4}$ Many professionals believe that this procedure is extremely uncomfortable to the patient, especially in surgeries performed under local anaesthesia. ${ }^{5}$ Freitas et al. evaluated the efficacy of SARME under local anaesthesia with midpalatal separation using a chisel, and the authors reported that all patients stated some discomfort during the surgical hammer beats used to split the maxilla in the median palatine suture. ${ }^{9}$ The literature on this issue is scarce. Studies are needed to evaluate the patient's subjective symptomatology, because surgeons must consider not only the efficacy of the technique but also the patient's perception when choosing the surgical procedure.

An increasing number of adults are presenting for orthodontic treatment, and the correction of a skeletal transverse discrepancy is required in many cases. Thus, the purpose of this study was to compare the immediate efficacy and the intraoperative and postoperative subjective assessment of symptomatology in patients undergoing SARME with and without midpalatal separation.

\section{Materials and methods}

After clinical evaluation and analysis of the initial orthodontic records, 24 adult patients (18 females and six males) were recruited consecutively into the study. The patients ranged in age from 18.3 to 31.8 years (mean $24.29 \pm 3.48$ years). The study inclusion criteria were as follows: transverse maxillary skeletal deficiency (>5 mm); skeletal maturity; presence of maxillary first premolars and maxillary first or second molars on both sides, with good structural and periodontal conditions to allow cementation and activation of the fixed expansion appliance; favourable physiological conditions of the cardiovascular system; no pre-existing medical contraindication to surgical procedures. Patients with severe asymmetry, limited periodontal health, and/or with congenital craniofacial deformities were excluded. This study was approved by the necessary institutional review board; written informed consent was obtained from all of the patients.

The patients were divided into two groups. Group 1 comprised 14 individuals who underwent SARME with midpalatal split (10 female, four male; mean age $24.44 \pm 3.22$ years). Group 2 comprised 10 individuals who underwent SARME without midpalatal separation (eight female, two male; mean age $24.08 \pm 3.81$ years). The Hyrax expander appliances (Hyrax II; Dentaurum, Ispringen, Germany) were cemented to the maxillary first molars and the first premolars. The appliances were scheduled for insertion as close as possible to the date of the surgical procedure. Two experienced senior oral and maxillofacial surgeons performed the surgeries. The surgeries were performed under local anaesthesia, as reported previously in the literature. ${ }^{4,5}$ The patients were not sedated because one of the objectives was to perform an intraoperative subjective assessment of the patient's symptomatology.

In group 1, the SARME was performed through the technique described by Bell, in which a partial bilateral maxillary osteotomy from the piriform aperture to the pterygomaxillary fissure is done. ${ }^{4}$ The pterygomaxillary sutures were kept intact. The midpalatal disjunction was made using a surgical hammer and a thin straight chisel positioned between the central incisors and directed towards the palatine direction. During surgery, the screws of the appliance were activated $2 \mathrm{~mm}$ (eight turns). After a 2-day latency period, the patients were instructed to activate the screw two turns $(0.5 \mathrm{~mm})$ twice a day, completing $1 \mathrm{~mm}$ of activation each day. ${ }^{4}$

In group 2, the technique proposed by Glassman et al. was used. ${ }^{5}$ A bilateral maxillary osteotomy was performed from the piriform rim to the zygomatic-maxillary buttress, ending just anterior to the pterygoid fissure, to break the resistance of the maxillary tuberosity and the contact between the maxilla and the zygomatic bones. The pterygomaxillary sutures were kept intact. The midpalatal suture was not separated during the procedure. During surgery, the screws were activated $1 \mathrm{~mm}$ (four turns). After a postoperative latency period of 2 days, the patients were instructed to activate the screw one turn $(0.25 \mathrm{~mm})$ twice a day, completing $0.5 \mathrm{~mm}$ activation each day. ${ }^{5}$

The degree of expansion was calculated for each patient; expansion was continued until an overexpansion of $2-3 \mathrm{~mm}$ was observed. After expansion, the screws were fixed using ligature wire to avoid mobility of the expansion screw. The difference in relation to activation was due to the surgical technical protocol recommendations followed. ${ }^{4,5}$

The patients in both groups received exactly the same postoperative medication and instructions. After the active treatment phase, the appliance was used as a passive retainer for 120 days. There were no dropouts or appliance failures during this study.

The efficacy of the technique was assessed in relation to the presence of a diastema between the upper incisors and radiographic evidence of separation of the maxillary bones in the midpalatal suture. To ensure that the midpalatal suture opened, a clinical evaluation was performed and an occlusal radiograph was taken immediately after the surgical procedure and at 14 days postoperative. Clinically, the suture opening was evaluated by the presence of a diastema between the maxillary central incisors. ${ }^{23}$ A senior oral and maxillofacial surgeon, who was not involved in the surgical procedure and who was blinded to the type of treatment, performed the clinical evaluation. For the radiographic evaluation, the midpalatal suture was considered open when a radiolucent area was observed in the suture region. ${ }^{23}$ A radiologist who was not involved in the surgical procedure and who was blinded to the type of treatment that had been performed conducted these evaluations. Failure was considered to have occurred if there was no evidence of a diastema between the maxillary central incisors and if an occlusal radiograph of the maxilla showed radiopacity at the alveolar crest between the maxillary incisors. In these cases, a new surgical procedure was performed after 14 days of postoperative follow-up, with midpalatal split. 
The patient's symptomatology was assessed using a questionnaire containing four questions: (1) How would you rate the discomfort of your surgery? (2) How would you rate the discomfort during appliance activation? (3) How would you rate your postoperative pain? (4) How would you rate your postoperative oedema? The first question was asked immediately after the surgical procedure and was repeated at 14 days postoperative. The other questions were asked only at postoperative follow-up (14 days postoperative) and addressed the degree of discomfort during the postoperative period.

The discomfort felt during and after the surgical procedure was measured using a pain and discomfort numerical visual analogue scale. ${ }^{24-26}$ The scores were assigned according to the answers to the questions relating to postoperative symptomatology and ranged from 0 to 10 . Scores of 0 to 2.5 indicated a comfortable procedure, without pain or oedema; scores of 2.6 to 5.0 indicated a tolerable procedure, with pain or a little oedema; scores of 5.1 to 7.5 indicated an uncomfortable procedure that was painful or with moderate oedema; and scores of 7.6 to 10 indicated an intolerable procedure with severe pain or severe oedema.

A power analysis using $\mathrm{G}^{*}$ Power software version 3.1.3 (Heinrich-Heine-Universität, Düsseldorf, Germany) showed that the sample size (10 per group) provided more than $95.3 \%$ power to detect a significant difference in efficacy between the groups at a significance level of 0.05 .

The mean, median, and standard deviation values for each variable were calculated for both groups. Fisher's exact test was used to evaluate the compatibility of the groups in relation to the sex distribution. The independent $t$-test was used to evaluate the compatibility of the two groups in relation to patient age. The Kolmogorov-Smirnov test was applied to determine the normality of the distribution of data. The treatment efficacy was compared between the groups using Fisher's exact test. To evaluate the subjective assessment of symptomatology between the groups, the Mann-Whitney test was used. The Wilcoxon test was applied to compare the answers for discomfort of the surgical procedure (question 1) immediately after surgery and at 14 days postoperative. For question 1, the Pearson correlation test was applied to compare the answers given immediately after surgery and at the 14-day postoperative assessment. The level of significance was set at $5 \%$. The statistical analyses were performed using Statistica version 5.1 software (StatSoft Inc., Tulsa, OK, USA).

\section{Results}

The groups were comparable with regard to sex distribution $(P=1.00)$ and initial patient age $(P=0.81)$.

\section{Efficacy of the technique}

A statistically significant difference in the efficacy of the technique was found between the groups $(P=0.00)$. Success was obtained for all patients in group 1 (efficacy $100 \%$ ), but in only three cases in group 2 (efficacy 30\%). For the other seven patients in group 2, it was necessary to perform a new surgical procedure at 14 days after the initial surgery. This complementary procedure consisted only of a midpalatal split, which was performed under local anaesthesia using a surgical hammer and a thin straight chisel positioned between the central incisors and directed towards the palatine direction, as recommended by Bell. ${ }^{4}$ Success was obtained for these seven patients after the midpalatal disjunction; all of them showed the presence of a diastema between the upper incisors and radiographic evidence of separation of the maxillary bones in the midpalatal suture after the second surgical procedure.

\section{Subjective assessment of symptomatology}

For both groups, the surgical procedure was initially classified as tolerable (question 1). No difference was observed between the groups (Table 1). At 14 days after surgery, when the first question was asked again, the patients in both groups considered the procedure as comfortable. Again, no statistically significant difference regarding the discomfort of surgery was observed between the groups (Table 1).

For both groups, the results showed an alteration in the perception of symptoms immediately after the procedure and at 14 days after the procedure. Comparing the discomfort of the surgical procedure, it was noted that the discomfort immediately following surgery was greater than that at 14 days postoperative for both groups (Table 2). After 14 days, the patients considered the procedure less uncomfortable than on the day of surgery. The Pearson correlation test showed a correlation coefficient of 0.88 for group 1 and 0.73 for group 2 .

In the evaluation of symptoms caused by activation of the expander (question 2), these were found to be tolerable for patients in group 1. In contrast, patients in group 2 found the appliance activation to be painful or uncomfortable. A statistically significant difference in the degree of discomfort during activation of the expander was found between the groups (non-parametric Mann-Whitney test; Table 1).

Although the medication prescribed and postoperative care were the same in the two groups, a statistically significant difference in postoperative pain (question 3)

Table 1. Comparison of symptoms between the groups. ${ }^{\text {a }}$

\begin{tabular}{|c|c|c|c|c|c|c|}
\hline & Group $^{b}$ & Rank sum & Mean rank & $U$-value & $Z$-value & $P$-value \\
\hline Question 1 & 1 & 201.5 & 14.39 & 43.5 & 1.58 & 0.11 \\
\hline Immediately postoperative & 2 & 98.5 & 9.85 & & & \\
\hline Question 1 & 1 & 196.5 & 14.3 & 48.5 & 1.28 & 0.19 \\
\hline 14 days postoperative & 2 & 103.5 & 10.35 & & & \\
\hline \multirow[t]{2}{*}{ Question 2} & 1 & 117.0 & 8.35 & 12.0 & -3.45 & $0.00^{\mathrm{c}}$ \\
\hline & 2 & 183.0 & 18.30 & & & \\
\hline \multirow[t]{2}{*}{ Question 3} & 1 & 136.5 & 9.75 & 31.5 & -2.30 & $0.02^{\mathrm{c}}$ \\
\hline & 2 & 163.5 & 16.35 & & & \\
\hline \multirow[t]{2}{*}{ Question 4} & 1 & 194.0 & 13.85 & 51.0 & 1.15 & 0.24 \\
\hline & 2 & 106.0 & 10.60 & & & \\
\hline
\end{tabular}

\footnotetext{
${ }^{a}$ Questions: (1) How would you rate the discomfort of your surgery? (2) How would you rate the discomfort during appliance activation? (3) How would you rate your postoperative pain? (4) How would you rate your postoperative oedema?

${ }^{\mathrm{b}}$ Group 1: SARME with midpalatal split. Group 2: SARME without midpalatal separation.

${ }^{\mathrm{c}}$ Significant at $P<0.05$.
} 
Table 2. Comparison of discomfort immediately postoperative and at 14 days postoperative by answer to question 1 for each group. ${ }^{\mathrm{a}}$

\begin{tabular}{|c|c|c|c|c|c|c|}
\hline Group & $\begin{array}{c}\text { Question 1 } \\
\text { Immediately postoperative Median }\end{array}$ & $\begin{array}{c}\text { Question 1 } \\
14 \text { days postoperative Median }\end{array}$ & $T^{+}$ & $T$ & Apr. Normal $Z$ & $P$-value \\
\hline 1 & 3.0 & 2.0 & 55.0 & 0.00 & 2.84 & $0.00^{\mathrm{b}}$ \\
\hline 2 & 2.25 & 1.5 & 36.0 & 0.00 & 2.56 & $0.01^{\mathrm{b}}$ \\
\hline
\end{tabular}

${ }^{a}$ Question 1: How would you rate the discomfort of your surgery?

${ }^{\mathrm{b}}$ Significant at $P<0.05$.

was found between them (Table 1). The symptomatology was significantly lower in group 1 compared to group 2 patients.

No difference was observed between the groups in relation to oedema in the postoperative period (question 4) (Table 1).

\section{Discussion}

Despite the advantages of SARME, there is a lack of consensus in the literature with respect to efficacy and the subjective assessment of symptomatology between surgical procedures performed with and without a midpalatal split. The present study relates some important observations that should be considered before selecting the treatment option. The efficacy of the procedures and the patients' experiences of these were evaluated in the present study.

The principal difference between the techniques compared in this study was the midpalatal split during the procedure. The results showed that the technique involving the midpalatal separation successfully enabled maxillary expansion, while without the split, the procedure failed in $70 \%$ of cases. The midpalatal separation is an effective procedure to ensure maxillary expansion. Employing a similar surgical technique to that used to treat group 1 patients, Freitas et al. showed that minimum osteotomies in the zygomatic pillars associated with a midpalatal osteotomy was effective in the treatment of adult transverse maxillary deficiency. ${ }^{9}$ Northway and Meade showed that the palatal width increased significantly when buccal corticotomy was accompanied by midpalatal split. ${ }^{21}$ Shetty et al., using a photoelastic model, demonstrated that midpalatal and pterygomaxillary osteotomies are essential for predictable skeletal expansion in adults, and the exclusive use of bilateral zygomatic buttress osteotomies appears to be inadequate. $^{27}$

Regarding the surgical procedure, the discomfort immediately after the procedure and at day 14 of the postoperative period was similar in the two groups (question 1). Both surgical techniques were tolerable to the patients under local anaesthesia. The use of a chisel for midpalatal separation did not form part of the patient's opinion of surgical discomfort.

Although patients in group 1 had a greater amount of screw activation per day, the symptomatology during screw activation was higher in group 2 patients (question 2). This probably occurred because of the lower amounts of loading on the anatomical structures after separation of the midpalatal suture. ${ }^{3}$ The maxillary expansion is facilitated by a greater amount of osteotomy. ${ }^{19}$ A more conservative surgical technique causes greater stress on the teeth and, therefore, a greater chance of pain during appliance expansion. $^{19}$

The postoperative pain was greater for group 2 patients than group 1 patients (question 3 ). This is probably associated with the pain during screw activation. The patients cannot disassociate themselves from these symptoms. The perceptions of postoperative oedema were similar in the two groups (question 4).

SARME can be performed either with the patient under general anaesthesia or under local anaesthesia. ${ }^{4}$ The selection of the type of anaesthesia should consider the surgical technique as well as the preference and behaviour of the patient. The patient's tolerance of pain must also be considered. ${ }^{21}$ General anaesthesia is preferred for invasive techniques, with no discomfort and a predictable outcome. When a more conservative surgical technique is chosen, ${ }^{4,5}$ local anaesthesia is an interesting option to reduce costs. $4,5,9,21$ The physical impact of local anaesthesia and the management of patients under local anaesthesia are similar to those of extraction procedures. ${ }^{21}$ In this study, the patients were treated under local anaesthesia because the two surgical approaches used are conservative and have previously been described in the literature as being performed under local anaesthesia., However, it is important to highlight that surgery performed under local anaesthesia should not bring about a reduction in the quantity of skeletal expansion. ${ }^{9}$

The suture opening was evaluated clinically in terms of the presence of a diaste- ma between the maxillary central incisors. Chamberland and Proffit demonstrated that the development of a diastema is a predictor that molar expansion has occurred. ${ }^{28}$ Occlusal radiographs and clinical evaluation were also used by Magnusson et al. to ensure that there was suture opening. ${ }^{23}$

Despite randomized, controlled, and blinded clinical trials being the gold standard for the evaluation of therapeutic interventions, such a design was not possible for the present study. Randomized controlled trials assessing surgical interventions are difficult. ${ }^{29}$ While surgeon and patient blinding were not possible in this study, the evaluation of efficacy was performed by two professionals who were not involved in the surgical procedure and who were blinded to the type of treatment. To validate the data, the compatibility of the groups was evaluated, ${ }^{30}$ and the results showed that the patients were comparable in terms of sex and age.

Studies evaluating different surgical techniques have used similar sample sizes. ${ }^{18,20}$ The power analysis demonstrated that the sample size was adequate to detect a significant difference between the two groups.

In conclusion, the surgical technique involving midpalatal separation was found to be more effective than the surgical technique without midpalatal separation. The surgical technique without midpalatal split failed in the vast majority of cases, and the patients showed worse postoperative pain and discomfort during expander activation. Both techniques were tolerable to the patients under local anaesthesia.

\section{Funding}

None.

\section{Competing interests}

None.

\section{Ethical approval}

Institutional Review Board of Bauru Dental School-University of São Paulo (protocol number \#66/2004). 


\section{Patient consent}

Not required.

\section{References}

1. Atac AT, Karasu HA, Aytac D. Surgically assisted rapid maxillary expansion compared with orthopedic rapid maxillary expansion. Angle Orthod 2006;76:353-9.

2. Holberg C, Steinhäuser S, Rudzki I. Surgically assisted rapid maxillary expansion: midfacial and cranial stress distribution. Am J Orthod Dentofacial Orthop 2007;132: 776-82.

3. Lee SC, Park JH, Bayome M, Kim KB, Araujo EA, Kook YA. Effect of bone-borne rapid maxillary expanders with and without surgical assistance on the craniofacial structures using finite element analysis. Am J Orthod Dentofacial Orthop 2014;145:638-48.

4. Bell RA. A review of maxillary expansion in relation to rate of expansion and patient's age. Am J Orthod Dentofacial Orthop 1982;81:32-7.

5. Glassman AS, Nahigian SJ, Medway JM, Aronowitz HI. Conservative surgical orthodontic adult rapid palatal expansion: sixteen cases. Am J Orthod 1984;86:207-13.

6. Pogrel MA, Kaban LB, Vargervik K, Baumrind S. Surgically assisted rapid maxillary expansion in adults. Int $J$ Adult Orthodon Orthognath Surg 1992;7:37-41.

7. Betts NJ, Vanarsdall RL, Barber HD, Higgins-Barber K, Fonseca RJ. Diagnosis and treatment of transverse maxillary deficiency. Int $J$ Adult Orthodon Orthognath Surg 1995;10:75-96.

8. Koudstaal MJ, Poort LJ, van der Wal KG, Wolvius EB, Prahl-Andersen B, Schulten AJ. Surgically assisted rapid maxillary expansion (SARME): a review of the literature. Int J Oral Maxillofac Surg 2005;34:709-14.

9. Freitas RR, Gonçalves AJ, Moniz NJ, Maciel FA. Surgically assisted maxillary expansion in adults: prospective study. Int J Oral Maxillofac Surg 2008;37:797-804.

10. Suri L, Taneja P. Surgically assisted rapid palatal expansion: a literature review. Am J Orthod Dentofacial Orthop 2008;133: 290-302.

11. Koudstaal MJ, Wolvius EB, Schulten AJ, Hop WC, van der Wal KG. Stability, tipping and relapse of bone-borne versus tooth-borne surgically assisted rapid maxillary expansion; a prospective randomized patient trial. Int J Oral Maxillofac Surg 2009;38:308-15.

12. Gurgel JA, Tiago CM, Normando D. Transverse changes after surgically assisted rapid palatal expansion. Int J Oral Maxillofac Surg 2014;43:316-22.

13. Knaup B, Yildizhan F, Wehrbein H. Agerelated changes in the midpalatal suture. $J$ Orofac Orthop 2004;65:467-74.

14. Angelieri F, Cevidanes LH, Franchi L, Gonçalves JR, Benavides E. Midpalatal suture maturation: classification method for individual assessment before rapid maxillary expansion. Am J Orthod Dentofacial Orthop 2013;144:759-69.

15. Northway WM. Palatal expansion in adults: the surgical approach. Am J Orthod Dentofacial Orthop 2011;140:463-9.

16. Verstraaten J, Kuijpers-Jagtman AM, Mommaerts MY, Bergé SJ, Nada RM, Schols JG. A systematic review of the effects of boneborne surgical assisted rapid maxillary expansion. $J$ Craniomaxillofac Surg 2010;38:166-74.

17. MacLaine JK, Thickett EM, Power SM. Nationwide survey of surgically assisted rapid maxillary expansion. Br J Oral Maxillofac Surg 2013;51:841-4.

18. Kilic E, Kilic B, Kurt G, Sakin C, Alkan A. Effects of surgically assisted rapid palatal expansion with and without pterygomaxillary disjunction on dental and skeletal structures: a retrospective review. Oral Surg Oral Med Oral Pathol Oral Radiol 2013; 115:167-74.

19. Assis DS, Xavier TA, Noritomi PY, Gonçales AG, Ferreira Jr O, Carvalho PC, et al. Finite element analysis of stress distribution in anchor teeth in surgically assisted rapid palatal expansion. Int J Oral Maxillofac Surg 2013;42:1093-9.

20. Sygouros A, Motro M, Ugurlu F, Acar A. Surgically assisted rapid maxillary expansion: cone-bean computed tomography evaluation of different surgical techniques and their effects on the maxillary dentoskeletal complex. Am J Orthod Dentofacial Orthop 2014;146:748-57.

21. Northway WM, Meade Jr JB. Surgically assisted rapid maxillary expansion: a comparison of technique, response, and stability. Angle Orthod 1997;67:309-20.
22. Chung $\mathrm{CH}$, Goldman AM. Dental tipping and rotation immediately after surgically assisted rapid palatal expansion. Angle Orthod 2003;25:353-8.

23. Magnusson A, Bjerklin K, Nilsson P, Jönsson F, Marcusson A. Nasal cavity size, airway resistance, and subjective sensation after surgically assisted rapid maxillary expansion: a prospective longitudinal study. $A m$ J Orthod Dentofacial Orthop 2011;140: 641-51.

24. Gracely RH, Dubner R, McGrath P, Heft H. New methods of pain measurement and their application to pain control. Int Dent $J$ 1978;28:52-65.

25. Huskosson EC. Measurement of pain. Lancet 1974;304:1127-31.

26. Kremer E, Atkinson JH, Ignelzi RJ. Measurement of pain: patient reference does not confound pain measurement. Pain 1981;10:241-8.

27. Shetty V, Caridad JM, Caputo AA, Chaconas SJ. Biomechanical rationale for surgical-orthodontic expansion of the adult maxilla. $J$ Oral Maxillofac Surg 1994;5:742-9.

28. Chamberland S, Proffit WR. Short-term and long-term stability of surgically assisted rapid palatal expansion revisited. Am J Orthod Dentofacial Orthop 2011;139:815-22.

29. Nada RM, Fudalej PS, Maal TJ, Bergé SJ, Mostafa YA, Kuijpers-Jagtman AM. Threedimensional prospective evaluation of toothborne and bone-borne surgically assisted rapid maxillary expansion. J Craniomaxillofac Surg 2012;40:757-62.

30. D'Agostino Jr RB, D'Agostino RB. Estimating treatment effects using observational data. JAMA 2007;297:314-6.

Address:

Célia Regina Maio

Pinzan-Vercelino

Alameda dos Sabiás

58

Portal dos Pássaros

Boituva

SP 18550-000

Brazil

Tel: +55 1533634976 ;

Fax: +551432271282

E-mail: cepinzan@hotmail.com 